\title{
GESTÃO DEMOCRÁTICA E INSERÇÃO DO SISTEMA NACIONAL DE AVALIAÇÃO NOS SISTEMAS MUNICIPAIS DE ENSINO DE SANTA CATARINA*
}

\author{
MANAGEMENT SYSTEM INTEGRATION AND DEMOCRATIC NATIONAL MUNICIPAL \\ SYSTEMS ASSESSMENT IN EDUCATION OF SANTA CATARINA
}

\author{
Almir Paulo dos Santos ${ }^{* *}$ \\ Doutor em Educação - UNISINOS | Brasil \\ E-mail: almirpaulo@yahoo.com.br
}

\begin{abstract}
REVISTA PEDAGÓGICA
Revista do Programa de Pós-graduação em Educação da Unochapecó | ISSN 1984-1566 Universidade Comunitária da Região de Chapecó | Chapecó-SC, Brasil ensino de Santa Catarina. Revista Pedagógica, Chapecó, v.15, n.31, p. 349-366 jul./dez. 2013.
\end{abstract} Como referenciar este artigo: SANTOS, A. P. Gestão democrática e inserção do sistema nacional de avaliação nos sistemas municipais de

RESUMO: a pesquisa identificou como a gestão democrática e o sistema nacional de avaliação se expressam, nos textos das leis de sistema municipal de ensino (SME), do Estado de Santa Catarina. O foco da pesquisa incide sobre as leis de criação dos sistemas municipais de ensino, em Santa Catarina. O estudo parte do aspecto legal de criação das leis de sistemas municipais de ensino, como pesquisa documental. Elenca o conteúdo expresso sobre a gestão democrática e a avaliação em larga escala, capaz de promover espaços de gestão democrática para a Educação municipal. A abordagem teórico-metodológica constituiu-se no ciclo de política de Stephen Ball, envolvendo o contexto da influência, o contexto da produção dos textos e o contexto da prática. A metodologia possibilitou a articulação entre os diferentes espaços da investigação, a partir do Banco de Leis de SME e de seus documentos oficiais. O estudo revela que das 170 leis de SME, 7\% não fazem referência à gestão democrática, 71 \% estão próximas do conteúdo da LDB/96 e 22\% articulam, em seu conteúdo, práticas de gestão democrática, no contexto da educação escolar e não ocorre a inserção do sistema nacional de avaliação. Por fim, destacamos que, quando as práticas estão conectadas ao contexto da Educação local, evidencia-se uma melhor gestão democrática.

PALAVRAS CHAVE: gestão democrática, avaliação em larga escala, sistema municipal de ensino.
ABSTRACT: research has identified as a democratic and national assessment system are expressed in the texts of the laws of the municipal school system (EMS), the State of Santa Catarina. The focus of the research focuses on the laws of creation of local systems of education, in Santa Catarina. The study of the legal aspect of creating laws local systems of education, as documentary research. It lists the contents expressed on the democratic management and large-scale assessment, capable of promoting democratic management spaces Educational municipal. The theoretical and methodological approach consisted in cycle policy Stephen Ball, involving the influence of context, the context of text production and the context of practice. The methodology enabled the articulation between the different areas of research, from the SME Bank Laws and their official documents. The study reveals that the 170 laws of SME, 7\% do not refer to democratic management, $71 \%$ are near $\mathrm{LDB} / 96$ content of $22 \%$ and articulate in its content, practice democratic management in the context of school education. Finally, we highlight that when the practices are connected to the context of Education site shows up better democratic management.

KEIWORDS: democratic management, large-scale assessments, municipal school system. 


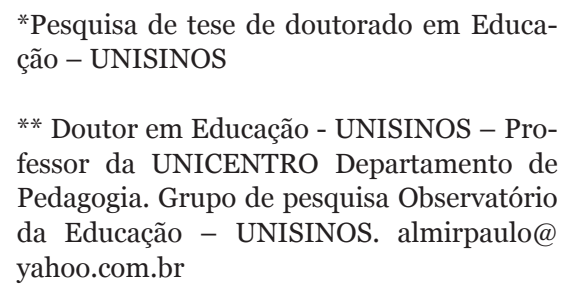

** Doutor em Educação - UNISINOS - Professor da UNICENTRO Departamento de Pedagogia. Grupo de pesquisa Observatório da Educação - UNISINOS. almirpaulo@ yahoo.com.br

\section{INTRODUÇÃO}

O trabalho a ser apresentado é parte integrante da pesquisa da tese de doutorado em Educação e tem por objetivo identificar como a gestão democrática e o sistema nacional de avaliação se expressam, nos textos das leis de sistema municipal de ensino (SME), do Estado de Santa Catarina. $\mathrm{O}$ foco da pesquisa incide sobre as leis de criação dos sistemas municipais de ensino, em Santa Catarina.

A abordagem teórico-metodológica da pesquisa, fundamenta-se nas concepções dos ciclos de políticas de Stephen Ball. Conforme Mainardes (2006), a proposta de abordagem do ciclo de políticas trabalha com a complexidade dos contextos políticos, interligando as instâncias do macro ao micro. Permite relacionar o macrocontexto com o microcontexto e vice-versa, estudando as influências mútuas e as mudanças que uma implementa na outra, potencializando os microcontextos. Cada um dos contextos apresenta arenas, lugares e grupos de interesses, envolvendo disputas e embates. Desse modo, embora cada contexto possua características específicas, eles se relacionam e dialogam compondo um ciclo, num movimento dinâmico e intenso de reflexões, produções e ações.

Os textos de políticas, ao mesmo tempo em que são produtos e produtores de orientação políticas, podem gerar situações de mudanças e inovações, através de sua difusão e promulgação. Isso significa que, dentro das arenas das práticas, estão sujeitos à interpretação e à recriação.

A apresentação do trabalho de pesquisa traz referências teóricas para o campo da gestão democrática da educação, postulando a sua importância e tendo enquanto objetivo trazer a reflexão para o contexto da prática educacional. Na seqüência, um debate sobre sistema municipal de ensino e o banco de leis do Estado de Santa Catarina, enquanto pesquisa documental empírica e um escopo de análise qualitativa dos dados. Refletir sobre políticas públicas municipais, demanda compreender e interferir no conjunto de propósitos e ações, entre as diversas instâncias, onde o mais importante são as mudanças que ocorrem nas práticas educacionais no contexto escolar.

\section{GESTÃO DEMOCRÁTICA DA EDUCAÇÃO}

A discussão sobre gestão democrática da Educação, no cenário das políticas educacionais, apresenta-se como um tema que tem sido objeto de vários estudos e pesquisas, tanto em nível nacional quanto internacional. Essa temática carrega, em seu contexto de articulação conceitual e prático, várias perspectivas, concepções e um cenário complexo de disputas e ressignificações. Diferentes atores e contextos institucionais assumem os processos de gestão, potencializando ações políticas, em meio a variáveis de influências e orientações. 
A gestão democrática da Educação emergiu no Brasil na década de 1980, a partir dos movimentos que resultaram em conquistas democráticas para a sociedade brasileira. Um dos pressupostos fundamentais de gestão democrática foi garantir uma escola pública, como a valorização dos profissionais. Desse modo, a gestão democrática da Educação passou a pensar a escola como espaço de política e trabalho, possibilitando reflexões e debates, com objetivos educacionais de contrapor os sistemas burocráticos e hierárquicos da administração escolar.

No Brasil, a Constituição Federal de 1988 abriu a possibilidade para um novo momento na democracia, evidenciando um compartilhamento do poder entre os entes federados. A União, o Distrito Federal, os Estados e os Municípios passaram a integrar-se em um novo modelo democrático, em regime de colaboração instituído legalmente. Houve, também, a afirmação do princípio da "gestão democrática do ensino público, na forma de lei” (art. 206, inciso VI), estendendo aos municípios o direito de organizarem seus sistemas de ensino, numa concepção de educação emancipadora, no sentido de exercício da cidadania.

A LDB de 1996 (Lei $n^{\circ}$. 9.394/96), considerando a autonomia entre os entes federados, remeteu aos sistemas de ensino a definição das "normas de gestão democrática do ensino público na educação básica”. Estabeleceu, como diretriz nacional, a "[...] participação das comunidades escolar e local em conselhos escolares ou equivalentes" (art. 14). O PNE, seguindo o princípio da Constituição e as diretrizes da LDB, definiu, entre seus objetivos e prioridades, a democratização da gestão do ensino público, nos estabelecimentos oficiais, obedecendo aos princípios da participação dos profissionais da Educação, na elaboração do projeto pedagógico da escola e na participação das comunidades escolares. A LDB (9.394/96) contempla a expressão "gestão democrática", significando a sua importância no contexto da administração. Salienta que a ideia de democracia, é apresentada de várias formas: gestão compartilhada, participativa e colegiada, fornecendo um importante pressuposto para a escola, como caminho para o exercício da democracia.

A Constituição, a LDB e o PNE estabelecem fundamentos e estratégias para a organização dos sistemas de ensino, assim como das práticas escolares. Um dos pressupostos essenciais é a gestão democrática do ensino público, estendida aos sistemas de ensino, como as escolas. Tal princípio da gestão democrática da Educação pública, pressuposto Constitucional e dispositivo legal, representa os valores e significações dos educadores que preconizam uma educação emancipadora, como exercício de cidadania numa sociedade democrática.

Enquanto princípio de Estado, na forma de lei, a gestão democrática deve constituir-se a partir das necessida- 
des da sociedade. Os cidadãos precisam ser ouvidos nas arenas políticas, tanto na elaboração de políticas, quanto na tomada de decisões. A gestão democrática fundamenta-se com a participação de todos, tanto nos aspectos administrativo-pedagógicos quanto, no sentido de compromisso sociopolítico. Esses espaços de participação podem ser constituídos no cotidiano escolar, de maneira consciente, contribuindo para a formação de pessoas que possam assumir o compromisso político, na transformação da sociedade.

Bordignon e Gracindo (2002) afirmam que a gestão democrática em sua constituição deve estar alicerçada num paradigma emergente, fundamentada por uma concepção dialética de realidade. O sujeito e o objeto do conhecimento exercem uma relação intersubjetiva, para compreender que o ser humano é um sujeito histórico, que sofre influência de seu meio atual, mas também tem a potencialidade histórica de intervir, construindo novos conceitos e saberes. Esse modelo de gestão vem se contrapor ao paradigma racionalista-positivista ou empírico-analítico, que está na base das orientações para a condução da gestão da Educação em um formato técnico-científico, caracterizado pela Modernidade.

A concepção sociocrítica de gestão democrática, proposta por Libânio (2003), contrapõe-se ao paradigma empírico-analítico. A construção de uma gestão democrática ocorre no contexto da prática. A reflexão crítica, a partir da realidade educacional, transforma a gestão, por meio participação dos sujeitos e do contexto. Contrapõe, muitas vezes, questões burocráticas impostas pelos sistemas. É nesse horizonte de reflexão que as práticas escolares se transformam, em práticas democráticas.

As instâncias de poder, numa gestão democrática, pressupõem uma inter-relação entre os atores, na tomada de decisão. Desse modo, a gestão nos espaços dos sistemas de ensino e nas escolas não é hierarquizada, mas coletiva. Nesse sentido, a reflexão torna-se o caminho metodológico na tomada de decisões e na constituição de políticas educacionais. Todos os atores que se envolvem nos sistemas educacionais participam da gestão, implicando em responsabilidades na organização dos sistemas de ensino, assim como de questões escolares. A participação e a autonomia tornam-se uma das referências importantes para a gestão democrática. Numa instituição a autonomia "significa ter poder de decisão sobre seus objetivos e suas formas de organização, manter-se relativamente independente do poder central, administrar livremente os recursos financeiros" (Libâneo, 2003, p. 115).

A Constituição Federal de 1988, em seu art. 206, apresenta o princípio inerente ao desenvolvimento do ensino nas redes escolares, o da gestão democrática do ensino público, na forma de lei, a gestão democrática 
da Educação nas Constituições Estaduais e nas Leis Orgânicas Municipais. Esta é uma das primeiras conquistas que os educadores não podem deixar de buscar em sua relação pedagógica, como princípio prático reflexivo. Desse modo, presente nas realidades regionais, locais, principalmente constituídas nos Sistemas Municipais de Ensino, a gestão democrática torna-se o fundamento essencial do exercício participativo, em suas diversas instâncias, Federais, Estaduais e Municipais.

Pensar a gestão democrática da Educação requer reflexão sobre as diversas instâncias que se formam, tanto em nível ideológico-administrativo, como nas ações escolares. A gestão, como pressuposto democrático, deve trilhar caminhos inversos aos dos organismos burocráticos modernos, fundamentados somente pelos parâmetros científicos e tecnológicos do capital. A construção demanda participar a partir do contexto da prática. É desse contexto que surgem as necessidades fundamentais, para que a coletividade e a democracia possam representar os anseios da sociedade. A gestão democrática ainda deve estar presente nas diversas instâncias - Federal, Estaduais e Municipais -, mesmo que os interlocutores do autoritarismo estejam conectados ao poder, em diversas decisões e atos burocráticos, resultando em ações individualizadas.

Esses espaços de lutas e conflitos possibilitam a reflexibilidade e uma mediação das políticas públicas, pensando a gestão a partir das necessidades, locais, regionais e escolares. É no contexto que são construídas as políticas públicas, a partir das reflexões coletivas, expressando as necessidades, de cada sociedade educacional. A gestão democrática caracteriza-se como condição de qualidade sociocultural da Educação. Isso implica dizer que não é suficiente garantir o direito à Educação, mas é necessária a participação dos sujeitos no contexto da prática escolar. Esses sujeitos produzem reflexões nos espaços escolares e fomentam os ideais de uma gestão democrática. A Educação precisa desse movimento de participação dos sujeitos. Isto abre a possibilidade democrática da gestão, tanto administrativa, quanto nos sistemas de ensino, na busca constante pela qualidade na Educação.

\section{SISTEMAS MUNICIPAIS DE ENSINO DO ESTADO DE SANTA CATARINA E O CON- TEXTO LOCAL}

Estudos e pesquisas vêm sendo realizados sobre Sistema Municipal de Ensino (SME), nas últimas décadas. Com a Constituição Federal de 1988, complementada pela LDB (9.394/96) definindo competências e atribuições dos entes federativos União, Distrito Federal, Estados e Municípios, em regime de colaboração, houve o estabelecimento, com clareza, da autonomia do município, para criar seu próprio sistema de ensino, assim como também ficou prevista sua integração ao sistema estadual. Destaca-se, aqui, 
o projeto de pesquisa "Mapa dos Sistemas Municipais de Ensino do Rio Grande do Sul” (Werle, 2007), que já realizou um levantamento de leis de criação de SME. O acompanhamento, a participação e o projeto das leis de criação dos SME, no Rio Grande do Sul, trouxeram questionamentos e reflexões, despertando o interesse em pesquisar a gestão democrática nas leis de SME, no Estado de Santa Catarina, e as implicações das avaliações em larga escala em dois municípios. Esse capítulo apresenta um contexto geral sobre o banco de leis de SME do Estado de Santa Catarina e analisa o conteúdo expresso da gestão democrática da Educação e avaliação.

A apresentação do banco de leis de SME, para o Estado de Santa Catarina, busca oferecer um panorama geral da legislação local. Na atualidade, o banco de leis de SME conta com 170 leis, dos 293 municípios catarinenses, compreendendo 58\% dos municípios do Estado. A identificação da legislação foi acontecendo, a partir de pesquisa junto ao site das prefeituras municipais, das associações dos municípios, bem como de maneira direta, com as secretarias municipais de ensino. Nesse universo da legislação, a análise documental fomentou dados para a pesquisa, bem como buscou elementos para pensar e refletir sobre as políticas de Educação municipal. O caminho a ser percorrido, neste texto, ocorrerá em dois momentos. No primeiro, será apresentado o banco de leis de SME, a partir de gráficos, situando como se construiu e distribuiu a legislação municipal no Estado de Santa Catarina, bem como em suas associações municipais. Num segundo momento, serão analisadas as 170 leis de SME, tendo como foco o conteúdo da gestão democrática e a inserção do sistema nacional de avaliação em larga escala. No decorrer das análises e dentro das possibilidades, serão apresentados pontos da pesquisa feita nas leis de SME do Estado do Rio Grande do Sul, com a perspectiva de auxiliar, confrontar e refletir sobre as políticas municipais no contexto do Estado de Santa Catarina.

As leis de SME são compreendidas como um documento, no qual se manifesta um conjunto de forças sociais, políticas e educacionais, no contexto da Educação local. Estão imbricados vários atores e elementos, que potencializam a formulação e reformulação da legislação educacional municipal. Em seu conteúdo legal, estão contidos elementos da Legislação Federal, assim como um conjunto de forças locais, que são estruturadas e se manifestam, por exemplo, a partir dos órgãos colegiados e dos espaços de participação da comunidade escolar. "As leis de SME abrangem muito mais do que apenas uma rede de escolas mantidas pelo governo municipal, incluindo organismos e ações de articulação do conjunto de forças sociais e políticas" (Werle, 2007, p. 03). Com a criação da lei de SME, potencializou-se um aumento da ação dos "[...] municípios para garantir recursos e espaços de participação na defesa 
dos interesses locais, sendo possível entender o reconhecimento do município como ente jurídico" (Sarmento, 2005, p. 1372).

A criação da lei de SME, para o município, pressupõe a conquista de sua autonomia local, como normatização e execução. É de responsabilidade dos atores locais (executivo, legislativo municipal, $\mathrm{CME}$, sindicato e associações de docentes, pais, alunos e cidadãos da localidade),legislativo municipal, CME, sindicato e associaçde SME do Estado do RS, enquanto pressuposto de auxiliar, confrontar dad a participação, de maneira direta ou indireta, modificando seu conteúdo, sua organização, quando isso se fizer necessário, para que o conjunto das ações pedagógicas e do sistema de ensino esteja voltado à qualidade da Educação local.

Podendo ser compreendidas como uma face das políticas e uma solidificação de interesses, as leis de SME são resultado de negociações, disputas e ressignificações. No momento de sua formulação, o resultado desses embates se transforma em documento legal, conduzindo aspectos específicos da Educação local. A sua formatação, no entanto, não se esgota em sim mesmo e nem oferece a única maneira de organizar a Educação local. A legislação, ao entrar em vigor, no contexto escolar e do sistema de ensino, pode sofrer interferência e ser reformulada, a partir das diversas práticas e dos sujeitos que se inter-relacionam.

O sistema de ensino municipal, suas unidades escolares e seus profissionais de educação, atuando em suas diversas práticas pedagógicas e de gestão, reproduzem a legislação vigente e também exercem um fenômeno de "infidelidade normativa", de fuga ao normativismo ou não aceitação da legislação em sua totalidade. Nesse sentido, Lima (2001) afirma que a escola não será apenas um lócus de reprodução, mas também um lócus de produção de políticas para a Educação. O envolvimento dos sujeitos escolares, suas reflexões e posicionamentos frente a sua própria realidade educacional, permite, muitas vezes, desconstruir a legislação provinda de maneira burocrática, sem a participação da comunidade local. Nesta direção, Ball (2006) analisa o desenvolvimento, a formação e a realização de políticas do contexto de influência até o contexto da prática. Ele tem observado, em sua abordagem sobre a trajetória das políticas, as formas pelas quais as políticas evoluem e se modificam, ao longo do tempo e do espaço. "Os professores e demais profissionais exercem um papel ativo no processo de interpretação e reinterpretação das políticas educacionais e, desta forma, o que eles pensam e acreditam têm implicação para o processo de implementação das políticas" (Mainardes, 2006, p. 98).

Os SME, em sua amplitude, são muito mais do que apenas redes de escolas, mantidas pelo governo municipal e organizadas pelas secretarias de Educação. Incluem um conjunto de organismos e ações que se articulam, refletem, 
potencializam, a partir das forças sociais e políticas da educação. "Os textos das leis condicionam e limitam a configuração institucional da educação e a ação dos educadores, mas também oferecem oportunidade de interação além de não perdurarem indefinidamente" (Werle, 2009, p. 3). Isso abre a possibilidade de rever aspectos da legislação, sobre como proporcionar mudanças no decorrer do tempo e do espaço, conforme as necessidades locais. As leis de SME carregam, em sua estrutura formal e de conteúdo, aspectos que possibilitam um direcionamento da Educação local. Os profissionais da Educação compreendem a legislação como mecanismo de controle burocrático, muito distanciando da realidade local. No contexto escolar, a "[...] palavra legislação tem um sentido largo que destaca, sobretudo, o caráter normativo e impositivo" (Lima, 2001, p. 142). Diante disso, parece que um caminho importante, para ser percorrido é o de aproximar a comunidade escolar, os gestores dos sistemas de ensino e a legislação municipal, conectando as leis ao contexto das práticas educacionais.

A lei não é uma normatização com caráter único e inquestionável. A formatação da legislação tem como fundamento a participação da sociedade, tendo como pano de fundo, as necessidades e as articulações éticas e morais, pelo qual a lei é criada. A participação da comunidade, nos diversos setores da sociedade, é um dos aspectos importantes para a solidificação das normas locais. Nem sempre, porém, a lei prevê a participação da comunidade. Instâncias do poder central e organismos internacionais explicitam seus interesses, controlando burocraticamente a Educação local. "Há uma preocupação dos organismos internacionais com a formação docente, sobretudo porque os professores são vistos de maneira incômoda pelo Banco Mundial” (Berenice, 2004, p. 4). Os profissionais da Educação, no contexto escolar, podem impulsionar a Educação local, a partir de seus anseios e necessidades. Nem sempre esses profissionais aceitam as imposições provindas dos diversos organismos internacionais, que, na maioria das vezes, são burocráticas e centralizadoras.

A participação da sociedade, por meio das diversas formas de organização das estruturas administrativas e políticas, é aspecto integrante na constituição da legislação. Quando a sociedade participa das instâncias da Educação municipal, é possível uma maior aceitação na aplicação da lei, assim como na sua reformulação. A legislação, do ponto de vista racional-legal, opera como referência para orientações normativas. "Um órgão existe a partir do momento em que é juridicamente previsto e normativamente criado" (Lima, 2001, p. 142). A legislação tem um caráter ético, de organizar os anseios da sociedade, podendo, nesse contexto de formulação da lei de SME, potencializar a participação dos diversos segmentos da Educação municipal. O envolvimento dos sujeitos e das entidades locais, como: gestores, professores, grêmio estudantil, conselho de pais, 
secretaria municipal de ensino e órgãos da comunidade em geral, pode contribuir em debates e reflexões, instituindo, com mais eficácia, as necessidades locais e formatando a legislação, a partir de suas necessidades.

Se não ocorrer a participação, na formulação da legislação, ela poderá provir de uma única instância, limitando-se à necessidade administrativa e de controle, configurando-se, então, como algo distante do contexto educacional local. Stromquist (1996) especifica que, na prática, as políticas públicas podem assumir múltiplas formas.

Cada vez mais essas políticas públicas estão sendo estabelecidas por organismos internacionais, por meio de conferências também internacionais, e criam para os países um compromisso moral de seguirem recomendações específicas, embora não sejam convenções e, portanto, não imponham nenhuma obrigação legal. (Stromquist, 1996, p. 27)

Há uma forte incidência de políticas externas e de suas influências para o contexto municipal, configurando interesses distantes da realidade local. A lei pode ser compreendida como um momento de equilíbrio de interesses e poder, uma condensação de forças, enquanto registro formalizado, que pode ser superado e envolvido por outras forças.

A dinâmica, o tempo, o espaço e a estruturação das políticas educacionais ocorrem em diferentes contextos, desvelando a complexidade com que as leis de SME são direcionadas. Observa-se que n esses movimentos das políticas ocorrem por processos diferenciados, experenciados em diferentes níveis, instituições, grupos, que ora reproduzem o que está formatado pela legislação, ora se movimentam pela não aceitação em sua totalidade. "Mesmo no seio da ordem jurídica existe um certo grau de desconexão normativa, que não deixará, certamente, de ser explorado pelos atores e utilizado em sua defesa" (Lima, 2001, p. 144). A "infidelidade normativa" assinala que as políticas podem adquirir múltiplas formas, em diferentes espaços e contextos. A formulação, a implementação e a explicitação legal, em contato com o contexto da prática educacional, são fatores que podem promover novas possibilidades de fazer políticas educacionais. As motivações e as reflexões, no contexto da Educação local, podem se constituir como caminhos significativos, para que os profissionais da Educação reinterpretem o contexto burocrático e mercadológico.

Projetos e ações do Governo Federal são associados à instância do município, como repasse de recursos e convênios, tendo se caracterizado como dificuldade de conduzir a educação local, delegando maior tempo e responsabilidades para o comprometimento desses projetos. Há uma "forte influência da União na definição de projetos e ações pelos governos locais" (Duarte, 2002, p. 13). 
Os textos legais podem ser compreendidos como o resultado de interações, de disputas e de forças que articulam interesses, modificando, ampliando ou até mesmo suprimindo. Isto pode ser decorrente de um processo de "bricolagem", de empréstimos, de cópia de fragmentos ou de ideias de outros contextos. Ball (2001) explicita que a maioria das políticas é frágil, constituindo-se produto de acordos e processos de influências, em sua produção. No contexto da prática, no entanto, é que as políticas podem ser modificadas e aperfeiçoadas. As leis de SME podem ser rearticuladas, no contexto escolar, assim como podem ser reproduzidas sem alterações. O importante é que a sua reconstrução seja orientada pela necessidade local. Ressalta-se que as leis de SME são uma das conquistas de políticas educacionais em nível local. São resultado de um movimento que atinge diferentes níveis municipais e associações, mas cria condições para que o município reveja seu próprio contexto educacional.

Há uma transferência de responsabilidade à Educação municipal, a partir da LDB (9.394/96), em seu art.11. O texto explicita que "os municípios incumbir-se-ão de: organizar, manter e desenvolver os órgãos e instituições oficiais dos seus sistemas de ensino, integrando-os às políticas e planos educacionais da União e dos estados" (BRASIL, 2010, p. 15). A legislação trouxe autonomia aos municípios, no sentido de eles poderem criar seus próprios SME; porém, isso demanda continuidade e comprometimento, entre as diversas instâncias da Educação local. Os gestores do Sistema Municipal de Ensino, suas unidades escolares e os profissionais que atuam no contexto da prática devem estar comprometidos com a qualidade da Educação local.

O banco de leis de SME do Estado de Santa Catarina tem esse intuito de identificar o conteúdo específico de gestão democrática da Educação e a inserção do Sistema Nacional de Avaliação. Na sequência, vamos apresentar o banco de leis de SME e, em seguida, analisar o conteúdo da gestão democrática e da avaliação.

\section{BANCO DE LEIS DE SME DO ESTADO DE SANTA CATARINA}

A construção do banco de leis de SME, para o Estado de Santa Catarina, tem por objetivo identificar o universo da legislação, presente nas instâncias municipais, para análise e interpretação do conteúdo específico da gestão democrática da Educação e a inserção do Sistema Nacional de Avaliação. A constituição do banco de leis de SME, para o Estado de Santa, iniciou-se por meio de levantamento de dados nos sites das prefeituras, das associações dos municípios, das câmaras de vereadores; por e-mail; mas, principalmente, pelo contato direto com as Secretarias de Educação em cada município. Ressalta-se a dificuldade em encontrar as leis de SME, mas, na maioria dos municípios, houve colaboração, para que chegássemos com um 
montante de $58 \%$ de municípios com leis de SME. Desse universo de leis, passou-se a organizar um mapeamento digitalizado, para iniciar a análise em cada uma das leis de SME.

O banco de leis está constituído na atualidade com 170 leis de SME, dos 293 municípios do Estado de Santa Catarina, correspondendo, aproximadamente, a 58\% da totalidade de municípios com leis de SME. Serão apresentados gráficos, por ano de criação das leis e por associações. Isso é importante, para identificar as leis de SME, visando à posterior análise. A pretensão é finalizar o banco de leis de SME para o Estado de Santa Catarina, o que permitirá ter o número total de municípios com leis de SME.

Dentre os 293 municípios no Estado de Santa Catarina, observa-se que a maioria é composta por municípios pequenos, com menos de 10.000 habitantes. Segundo indicadores do IBGE (2010), para o Estado catarinense, é o caso de 174 municípios, compreendendo 60\% dos municípios de pequeno porte. Veiga (2003) apresenta que, embora não seja somente uma preocupação meramente contábil populacional, existe a necessidade de uma renovação do pensamento brasileiro sobre as tendências de urbanização e de suas implicações sobre as políticas de desenvolvimento que o Brasil deve adotar.

A Constituição Federal de 1988 e a LDB/96 redefiniram o papel institucional, instaurando um novo pacto federativo nas diferentes esferas do poder, proporcionando certo grau de autonomia aos municípios, consolidando, portanto, como ente jurídico com recursos e com responsabilidades próprias, tendo liberdade para constituir seu próprio Sistema Municipal de Ensino. A criação do SME possibilita um avanço na Educação local, assim como agiliza os processos relacionados às instituições educacionais no município. Já a criação de lei de SME é uma referência histórica importante para o contexto geográfico, social, político e da legislação, na instância municipal. Magalhães (2006) afirma que a Constituição de 1988 atribuiu aos municípios competências e possibilitou a participação em impostos arrecadados pela União e Estados, mas, em contrapartida, foi ampliada a esfera de obrigações dos municípios, na prestação de serviços essenciais.

A LDB/96 enfatiza o art. 211 da Constituição, estabelecendo competências aos Estados, Distrito Federal e Municípios, em regime de colaboração permanente, compreendendo uma conjugação de ações, entre órgão e instituições, como de ordem normativa e executiva. Com a criação da lei de SME, o município insere-se no processo político democrático, consolidado pelo regime federativo, enquanto autônomo. Atua em função das necessidades e objetivos próprios de sua região, mas está submetido às diretrizes gerais da Educação nacional, garantindo o direito à Educação escolar de qualidade, proporcionando um es- 
paço de envolvimento das lideranças locais, bem como dos sujeitos, interligados ao sistema de ensino do município.

Com esse montante de $58 \%$ dos municípios, com leis de SME, do Estado de Santa Catarina, identificamos que, até o ano de 2000, foram criadas 88 leis SME, compreendendo 30\% da legislação dos municípios. A partir da LDB/96, muitos municípios sentiram-se impulsionados a constituir seu próprio SME em Santa Catarina, possibilitando conquistar a autonomia educacional local. Werle (2007) também identifica, em sua pesquisa no Rio Grande do Sul, que a LDB/96 foi um elemento desencadeador da organização da Educação, no nível dos municípios, pois, logo após a sua promulgação, vários municípios do Rio Grande do Sul criaram seus SME.

Para o Estado de Santa Catarina, a LDB foi um elemento desencadeador, no sentido de que os municípios criassem seus SME e organizassem a Educação local. Logo após a sua promulgação, vários municípios do Estado de Santa Catarina criaram seus SME. O gráfico possibilita identificar, por ano, o número de municípios que criaram a lei de SME.

Gráfico 1: Número de Municípios do Estado de Santa Catarina, com Lei de Criação dos SME, por ano de criação.

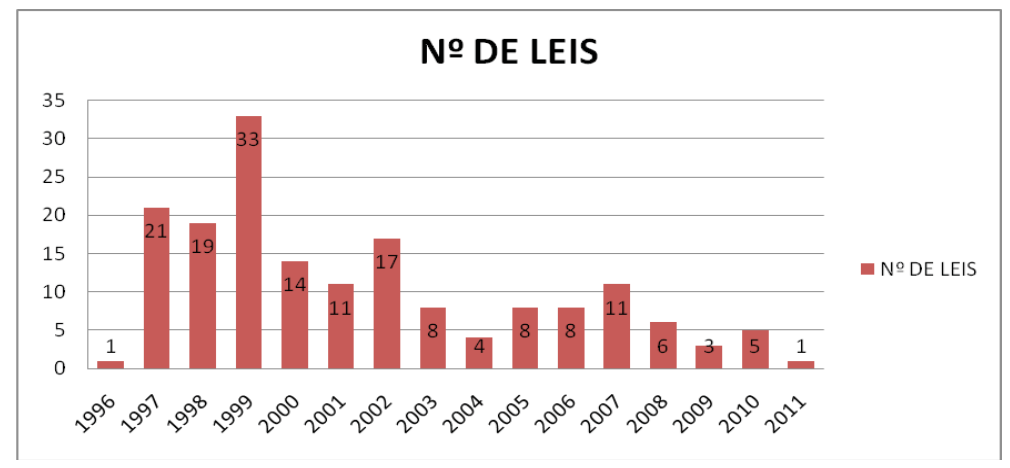

FONTE: Banco de Leis de Criação de SME de Santa Catarina

O gráfico acima apresenta o banco de leis de criação de SME, com 170 leis, o que representa $58 \%$ dentre o total dos 293 municípios do Estado de Santa Catarina. A LDB/96 definiu as competências e as atribuições dos entes federativos, assim como estabeleceu, com clareza, a autonomia para os municípios criarem seu sistema de ensino. No mesmo ano de criação da LDB/96, o município de Braço do Trombudo, localizado no do Alto Vale do Itajaí, criou a sua lei de SME. Logo após a LDB/96, 12\% dos municípios, no ano de 1997, criaram seus sistemas municipais de ensino. Esses 12\% de municípios estão localizados em duas regiões específicas: a do Oeste de Santa Catarina e a do Vale do Itajaí. São dados parciais, justamente por não ter a totalidade de municípios e suas leis de SME. Identificamos, porém, que são regiões de destaque no desenvolvimento econômico do Estado de Santa Catarina. O Oeste, pela agricultura, 
e o vale do Itajaí, por ser uma região portuária. Esses fatores podem ter impulsionado os municípios na criação de suas leis de SME, conjuntamente com o desenvolvimento da economia local. Sarmento (2005) explicita que uma das causas da criação de leis de SME é o aumento da ação dos municípios, no sentido de garantir recursos e espaços de participação, na defesa dos interesses locais. Outro fator mencionado é o reconhecimento do município como ente jurídico, conquistando sua autonomia para atuar em regime de colaboração com o Estado e a União.

No ano de 1998, 11\% de municípios criaram leis de SME. Observamos que essas legislações são criadas em diferentes regiões do Estado de Santa Catarina, não mais em regiões específicas. No ano de 1999, 19\% de municípios criaram leis de SME. É o ano com o maior número de leis, relativas à criação do SME do Estado de Santa Catarina, também localizadas nas diversas regiões do Estado. De 2000 a 2003, foram criadas leis de SME, em 29\% de municípios. Dos anos de 2004 a 2011, 28\% de municípios passaram a ter leis de SME.

O banco de leis de SME do Estado do Rio Grande do Sul identificou que, nos anos de mudanças de governo municipal, há um impulso diferenciado, quanto ao número de criação de leis de SME. Já no banco de leis de SME do Estado de Santa Catarina, isso não se confirmou.

Gráfico 2: Número de Municípios de Santa Catarina com sistema municipal de ensino, por associação de Municípios.

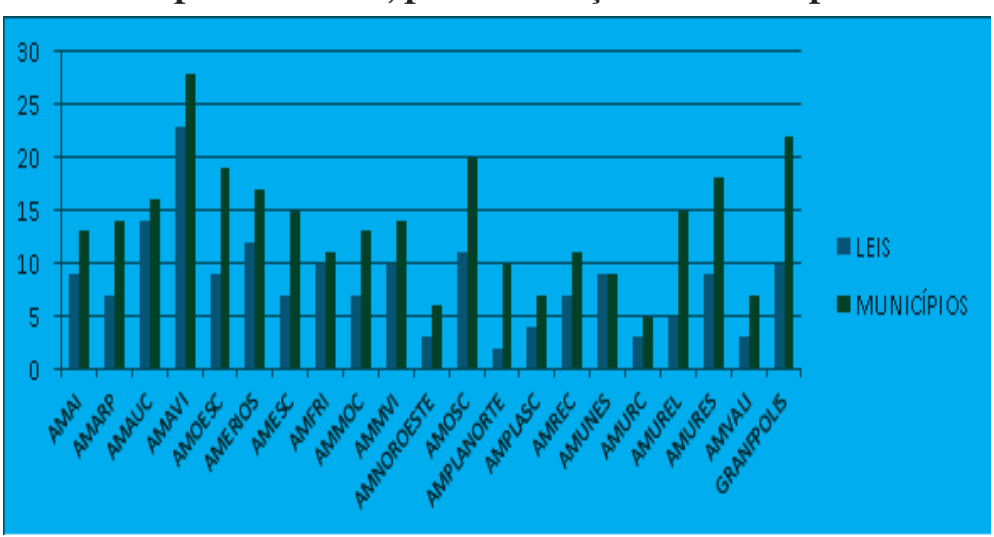

Fonte: Banco de Leis de Criação de SME de Santa Catarina

O gráfico acima identifica o número de municípios com SME em suas associações municipais. O Estado de Santa Catarina conta com vinte e uma associações municipais espalhadas em diferentes regiões, com uma diferenciação na quantidade de municípios, em cada associação. Três associações aparecem como destaque, em relação ao número de municípios e de leis. São a Associação dos Municípios do Vale do Itajaí (AMAVI), a Associação dos Municípios da Grande Florianópolis (GRANFPOLIS) e a Associação dos Municípios do Oeste Catarinense (AMOSC). A Associação dos Municípios do Vale do Itajaí (AMAVI) conta com um número de 28 municípios e com 23 leis de criação de SME. 
É maior associação de municípios do Estado de Santa Catarina. Conforme análise do banco de leis de SME, feita anteriormente, é uma das associações que tiveram um grande número de municípios que criaram leis de SME, logo após a LDB/96. A segunda associação de municípios, a GRANFPOLIS, conta com 22 municípios e aproximadamente 10 leis de criação dos SME; e a AMOSC, com 20 municípios. A AMOSC também tem como característica o fato de que um número elevado de seus municípios criou leis de SME, logo após a LDB/96. Há uma grande diferenciação quanto ao número de municípios, nas diferentes Associações, mas podemos afirmar que a lei de SME é uma das conquistas da autonomia educacional no município, possibilitando a construção da qualidade educacional local.

As leis de SME, para o Estado de Santa Catarina, possibilitaram entender a autonomia conquistada pela Educação local. Essa autonomia não deve se esgotar em si mesma, mas por ações coletivas, que tenham o intuito de desenvolver uma gestão democrática. A gestão do Sistema Municipal de Ensino, interligada aos documentos legais com o contexto da prática educacional local, pode ser um caminho possível para melhorar o ensino-aprendizagem de cada sujeito, no contexto escolar, tendo em vista a qualidade da educação municipal. A comunidade escolar é uma das referências importantes para que a legislação municipal, com o passar do tempo, absorva práticas democráticas, provenientes do contexto educacional local, em seu conteúdo. É o que observamos, tendo em vista que a lei de SME é uma possibilidade de construir práticas democráticas na Educação municipal.

\section{CONSIDERAÇÕES FINAIS}

O trabalhou buscou evidenciar como a gestão democrática é apresentada no conteúdo expresso das leis de SME do Estado de Santa Catarina. Para isso, constituiu-se da coleta de leis de SME e a formatação de um banco de leis de SME do Estado de Santa Catarina. O contato ocorreu por e - mail, nas páginas das prefeituras municipais, nos documentos das legislações do Estado de Santa Catarina e diretamente com a instância municipais e seus representantes da educação. Ressalta-se a dificuldade em alguns municípios, como também a presteza e as contribuições das equipes das secretarias municipais de educação dos municípios que atualmente constituem o banco de leis de SME.

Das 170 leis de SME, de Santa Catarina, analisadas, encontramos $7 \%$ que não apresentam o conteúdo da gestão democrática. O segundo nível em que há menção à gestão democrática representou $71 \%$ do montante da legislação. Estas se encontram muito próximas ao conteúdo da LDB/96 ou à Legislação Federal. O terceiro nível alcançou 22\% do total do banco de leis de SME, de Santa Catarina, demonstrando que, mesmo tendo referência à LDB/96, 
traz explícita a importância da gestão democrática nos diversos níveis do SME. Essa análise qualitativa da legislação representa, de maneira geral, as especificidades que condensam aspectos das políticas em seus diversos níveis.

As leis de SME que não explicitam o conteúdo da gestão democrática da Educação, com $7 \%$, apresentam um número de títulos, capítulos e artigos muito reduzidos, em sua estrutura formal. A lei é apresentada com o título "Dos Princípios da Educação Básica". A segunda categoria analisada obteve $71 \%$ do montante dos $58 \%$ de municípios que possuem lei de SME, em Santa Catarina. Neste caso, conforme foi mencionado, verificamos a formulação muito colada ao texto da LDB e a documentos legais federais. A maioria das leis analisadas nessa categoria tem um capítulo específico, que às vezes é idêntico às formulações da LDB. Temos que considerar que a criação das leis de SME tornou-se possível, a partir da Constituição Federal de 1988 e da LDB/96. A legislação previa, ao município, a opção de criar seu próprio sistema, de compor com o Estado um sistema único ou de manter-se integrado ao sistema estadual. A criação de seu SME proporcionou autonomia aos municípios. As leis de SME que demonstram interações com a realidade local, trazendo aspectos reflexivos na reconstrução dos espaços escolares e do próprio sistema de ensino, estão conectadas ao terceiro nível de análise. Das 170 leis de SME analisadas, 22\% apresentam essa estrutura documental, no sentido de pensar a gestão democrática, não somente como fundamentação da LDB/96 ou da Legislação Federal, mas como algo que constrói a autonomia do município, a partir das diversas entidades da comunidade. Essas leis de SME desdobram o tema gestão democrática de diferentes maneiras: ações coletivas e prática política, autonomia escolar, práticas de gestão participativa no SME e na escola, e gestão democrática em regime de colaboração. Porém, referente à inserção do sistema nacional de avaliação no banco de leis de SME é considerada nula. As leis de SME de Santa Catarina não explicitam a inserção do sistema nacional de avaliação. Sabemos que a quase duas décadas as avaliações estão ocorrendo no contexto da educação, apresentando índices. Esse tema será assunto de outro trabalho a ser apresentado tendo o intuído de identificar quais seriam os fatores das leis de SME não acolher o sistema nacional.

Para concluir, em algumas leis de SME, há formulações que denotam ações coletivas e práticas políticas. Em geral, indicam um planejamento coletivo de ações para formulações e reformulação de políticas. As ações e as práticas apresentam-se imbricadas, tentando articular diversas participações coletivas, que fortalecem a gestão democrática. Dentre elas, estão as mais evidentes: participação dos profissionais da Educação nos espaços escolares; participação da comunidade escolar e local nos conselhos escolares; participação efetiva na escolha dos dirigentes e coorde- 
nadores; escolha de dirigente através de processo eletivo, com a participação dos diversos segmentos da comunidade escolar; gerenciamento autônomo das questões pedagógicas e financeiras; respeito à autonomia de organização dos segmentos de pais, professores e estudantes. Quanto mais próxima das práticas educacionais a leis de SME estiverem, melhor será o ensino aprendizagem e a conquista autonomia pedagógica escolar.

\section{REFERÊNCIAS}

ALVES, Fátima; BONAMINO, Alícia; FRANCO, Creso. Qualidade do ensino fundamental: políticas, suas possibilidades, seus limites. Educação e Sociedade, Campinas, v. 28, n. 100, Especial, p.989-1014, out.2007.

BALL, Stephen. J. Educação à venda. Viseu: Editora Pretexto, 2005. (Coleção Discursos).

. Mercados educacionais, escolha e classe social. In: GENTILE, Pablo (org.) Pedagogia da exclusão. Petrópolis: vozes, 2006. p. $196-227$.

BONAMINO, Alicia Catalano. Avaliação da educação básica. São Paulo: Ed. Loyola, 2004.

. Três Gerações de Avaliação da Educação Básica no Brasil. Educação e Pesquisa, São Paulo, v. 38, $n^{\circ}$, 2012.

BORDIGNON, Genuíno; GRACINDO, Regina Vinhaes. Gestão da Educação: município e escola. In: FERRERIA, Naura; AGUIAR, Márcia (Orgs.) Gestão da educação: impasses, perspectivas e compromissos. São Paulo: Cortez, 2002.

CASTRO, Maria Helena G. de. A Consolidação da Política de Avaliação da Educação Básica no Brasil. Rio de Janeiro, v. 1, n. 3, p.271-296, set./ dez. 2009.

DUARTE, Marisa Ribeiro Teixeira. Relações intergovernamentais e regime de colaboração: o atendimento público na educação escolar básica. In: REUNIÃO ANUAL DA ANPED, 24., 2001. Caxambu. Banco de Papers. GT Estado e Política. Caxambu: ANPED, 2002. Disponível em http:/www. anped.com.br. Acesso em: 27 de novembro 2011.

BRASIL. Constituição. Constituição da República Federativa do Brasil. Promulgada em 5 de outubro de 1988. 37. ed. Atual. e ampl. São Paulo: Saraiva, 2005.

Lei n. 9.394, de 20 de dezembro de 1996. Fixa diretrizes e bases da educação nacional. Diário Oficial da União, Brasília, 23 dez. 1996. 
CURY, Carlos Roberto Jamil. Gestão democrática da educação pública. Gestão democrática da educação, Brasília, Boletim 19, p. 14-19, out. 2005.

FRANCO, Creso. Avaliação da Educação Básica. Educação \& Sociedade, Campinas, v. 28, n. 100, p. 989-1014, out. 2004.

GATTI, Bernardete A. Avaliação dos Sistemas Educacionais no Brasil. Ciência e Educação, São Paulo, V. 09 maio/agosto, 2009.

LIBÂNEO, José Carlos. Organização e Gestão da Escola. Goiânia: Alternativa, 2003.

LIMA, Licínio C. A escola como organização educativa. Cortez São Paulo: 2001.

MAINARDES, Jefferson. Abordagem do ciclo de políticas. Educação e Sociedade, Campinas, v. 27, n. 94, p. 4794, 2006.

OLIVEIRA, João Ferreira de; TOSCHI, Mirza Seabra. Educação Escolar: políticas, estruturas e organização. São Paulo: Cortez, 2004.

SARMENTO, Diva Chaves. Criação dos Sistemas Municipais de Ensino. Educação e Sociedade: Campinas, vol. 26, n. 93, p. 1363-1390, Set./Dez. 2005.

SOUSA, Sandra M. Zakia L. de. Avaliação e carreira do magistério: premiar o mérito? Revista Retratos da Escola, Brasília, v. 2, n. 2-3, p. 81-93, jan/dez. 2008.

STROMQUIST, Nelly. Políticas Públicas de Estado e equidade de gênero. Revista Brasileira de Educação, Rio de Janeiro, n. 1, p. 16-28, jan./abr. 1996.

VIANNA, Heraldo Marelim. Fundamentos de um programa de avaliação educacional. Brasília: Ed. Líber, 2005 .

WERLE, Flávia Obino Corrêa. Sistemas Municipais de Ensino como contexto da gestão democrática e dos Conselhos Escolares. In: SIMPÓSIO BRASILEIRO, LUSO-BRASILEIRO, COLÓQUIO IBERO-AMERICANO DE POLÍTICA E ADMINISTRAÇÃO DE EDUCAÇÃO - ANPAE, 23 - 51., 2007. Porto Alegre, 12 -14 de novembro de 2007.

VEIGA,José Eli da. Cidades imaginárias: o Brasil é menos urbano do que se calcula. Campinas: Autores Associados, 2003. 
WERLE, Flávia; MANTAY, Carla; ANDRADE, Alenis Cleusa de. Direção da Escola Básica numa Perspectiva Municipal. Educação, Porto Alegre, v. 32, n. 2, p. 139-149, mai./ ago. 2009.

Avaliação em Larga Escala Foco na Escola. In:FICHER, Beatriz T. D. Avaliação da Aprendizagem: a obsessão pelo resultado pode obscurecer a importância do processo. Oikos, São Leopoldo: 2010. 